\title{
Thermal Stress, Aggregation of Chlorophyll-Protein Complexes, and Light-Dependent Recovery of PSII activity in Wheat Seedlings
}

\author{
M. S. Khristin ${ }^{a}$, T. N. Smolova ${ }^{a, *}$, and V. D. Kreslavski ${ }^{a}$ \\ ${ }^{a}$ Institute of Basic Biological Problems, Russian Academy of Sciences, Pushchino, Moscow oblast, 142290 Russia \\ *e-mail:smolova_20@rambler.ru \\ Received December 22, 2020; revised February 15, 2021; accepted February 17, 2021
}

\begin{abstract}
The dynamics of changes in the photochemical activity of photosystem II (PSII) and low-temperature spectra at $77 \mathrm{~K}$ in the first leaves of 11-day winter wheat plants Triticum aestivum $\mathrm{L}$., as well as structural changes in chlorophyll-protein complexes (CPC) of thylakoid membranes during recovery after a short-term (20 min) heating at a temperature of $42^{\circ} \mathrm{C}$, were studied. Changes in the $F_{\mathrm{v}} / F_{\mathrm{m}}, \mathrm{F} 735 / \mathrm{F} 695$, and F735/F685 ratios indicate inhibition of PSII immediately after heating. Using nondenaturing electrophoresis, it was shown that the light-harvesting $\mathrm{Chl} a / b$ complex of PSII does not aggregate immediately after heating but after several hours, after $6 \mathrm{~h}$ the desagregation of CPC was observed, which was consistent with an increase in the $F_{\mathrm{v}} / F_{\mathrm{m}}$ ratio upon recovery. The influence of temperature, intensity, and quality of light (white, blue, and red light) on the recovery of PSII activity and low-temperature fluorescence spectra was studied. It was concluded that the recovery is a photo-activated low-energy process, independent of photosynthesis, and the most effective in blue light.
\end{abstract}

Keywords: Triticum aestivum, recovery of photochemical activity, heat stress, photosystem II, chlorophyllprotein complexes

DOI: $10.1134 / \mathrm{S} 1021443721050071$

\section{INTRODUCTION}

Reversible inhibition of photosynthesis is one of the mechanisms of plant adaptation to the action of many stress factors [1], and the degree of photoinhibition depends on the balance between photodamage and the PSII recovery mechanism [2]. However, the mechanisms of inhibition of photosystems and their recovery in various stressful situations, in particular, during a short-term increase in temperature, have not been adequately studied. It is believed that the remaining activity of the photosynthetic apparatus (PSA), reduced as a result of heat stress, depends on the intensity and quality of light, which are one of the determining factors [3-5]. Meanwhile, the mechanisms of the action of short-term heat stress on photosynthesis and the ways of recovery of photosynthetic function after thermal inactivation are poorly understood. One such stress-protective mechanism of PSA against heating and photoinhibition may be the reversible aggregation of chlorophyll-protein complexes (CPC) of photosystems as well as denaturation of CPC [6]. Another defense mechanism is the redistribution of excitation energy between the photosystems: the LHC II from the area where this photosystem is localized can move to the area where PSI is localized, due to which the energy absorbed by the LHC II enters mainly PSI,

Abbreviations: Chl-chlorophyll; OEC-oxygen-evolving complex; PSA-photosynthetic apparatus. which is more resistant to stress, in particular to heat [7], than PSII [8]. Low molecular weight compounds, such as proline, glycine betaine, and choline-containing compounds, may also be important in increasing resistance to heat stress $[9,10]$.

At the same time, a simultaneous study into the dynamics of changes in the photochemical activity of leaf chloroplasts and structural changes in the CPC of thylakoid membranes has not been previously performed. The study of these dynamics could help to identify a relationship between photochemical changes in chloroplasts and structural changes in the CPC of photosystems.

The goal of the study was to investigate the effect of short-term heat stress at $42^{\circ} \mathrm{C}(20 \mathrm{~min})$ on the dynamics of the light-dependent recovery of the photochemical activity of PSII, coupled with the restoration of the electrophoretic mobility of CPC. We assumed that the reversible structural and functional changes in the CPC of photosystems are a protective mechanism for the dissipation of excess excitation energy due to inhibition of the $\mathrm{CO}_{2}$ assimilation system and/or the oxygen-evolving complex (OEC) of PSII during thermal inactivation.

\section{MATERIALS AND METHODS}

In the experiments, we used 11-day-old seedlings of winter wheat (Triticum aestivum L.) variety 


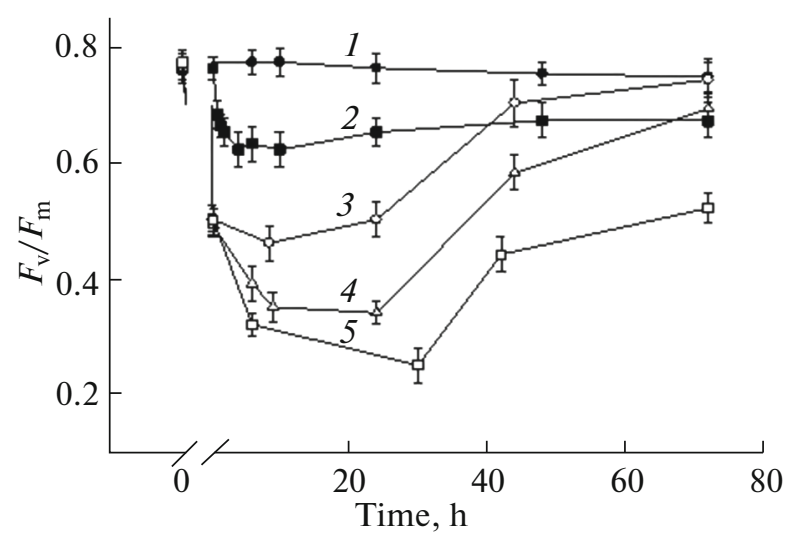

Fig. 1. Changes in the maximum quantum yield of PSII $\left(F_{\mathrm{v}} / F_{\mathrm{m}}\right)$ in the leaves of 11-day winter wheat seedlings exposed (white symbols) and not exposed (black symbols) to heat stress at $42^{\circ} \mathrm{C}(20 \mathrm{~min})$. After heating, the seedlings were grown in low, moderate, and strong light at $22^{\circ} \mathrm{C}(n=10)$. (1) control, faint light; (2) control, strong light; (3) heating, faint light; (4) heating, moderate light; (5) heating, strong light.

Moskovskaya 35. The plants were grown on sand with the addition of Knop's nutrient solution at a light intensity $I=150 \mu \mathrm{mol}$ PAR quanta $/\left(\mathrm{m}^{2} \mathrm{~s}\right)$ obtained from DRLF400 lamps with a photoperiod of $16 \mathrm{~h}$, at a temperature of $22^{\circ} \mathrm{C}$. Plants of the same size were selected for the experiments and the seedlings were placed in an MLW U2 water thermostat (VEB MLW PRUFGERATE WERK MEDINGEN, DDR) at $42^{\circ} \mathrm{C}$ (20 min), completely immersing the seedlings in water. The seedlings were then placed in Knop's nutrient solution and kept under the same conditions as before heating but at different light intensities (weak at $60 \mu \mathrm{E} /\left(\mathrm{m}^{2} \mathrm{~s}\right)$, moderate at $300 \mu \mathrm{E} /\left(\mathrm{m}^{2} \mathrm{~s}\right)$, strong at $\left.800 \mu \mathrm{E} /\left(\mathrm{m}^{2} \mathrm{~s}\right)\right)$ at $22^{\circ} \mathrm{C}$. During recovery, we used three illumination options using white, red, and blue LEDs (TH NEON, Russia), the characteristics of which were verified using an S100 wide-range spectrometer (Solar Laser Systems, Belarus). The maxima of the emission bands of blue LEDs are $463 \mathrm{~nm}$, red blue LEDs are $656 \mathrm{~nm}$, and the half-width of the bands is approximately $20 \mathrm{~nm}$. In a number of experiments, chloramphenicol was added to the nutrient mixture at a final concentration of $0.001 \mathrm{M}$.

PSII activity was measured in the first leaves of seedlings using the variable fluorescence method with a phosphoroscope [11]. Fluorescence was excited with blue light with $\lambda \mathrm{m}=480 \mathrm{~nm}\left(0.15 \mathrm{~W} / \mathrm{m}^{2}\right)$, which was focused on an area of $5 \times 20 \mathrm{~mm}$ in the upper third of the leaf surface. Acting light $\left(100 \mathrm{~W} / \mathrm{m}^{2}, \lambda>660 \mathrm{~nm}\right)$ was passed through a KS18 glass light filter (LOMO, Russia). The measured parameters were $F_{0}, F_{\mathrm{v}}, F_{\mathrm{m}}, F_{0}$, and $F_{\mathrm{m}}$ (levels of the initial and maximum fluorescence of Chl $a$, respectively [12]) and $F_{\mathrm{m}}$ (lightinduced changes in the fluorescence of Chl $a$ ). The maximum quantum yield PSII, $F_{\mathrm{v}} / F_{\mathrm{m}}$ ratio, was calculated.
Structural changes in CPC complexes were analyzed by measuring low-temperature fluorescence spectra upon excitation with light $\lambda_{\mathrm{m}}=435 \mathrm{~nm}$ and excitation of leaf fluorescence $\left(\lambda_{\mathrm{m}}=685 \mathrm{~nm}\right)$ at $77 \mathrm{~K}$ using a Hitachi-850 spectrofluorometer (Hitachi Ltd., Japan). The excised leaves were placed in glass tubes and then in a Dewar flask with liquid nitrogen, which was installed in the fluorometer measurement chamber. The number of measurements in each experiment was at least three. At the same time, the optimal direction of the exciting light $\left(\lambda_{\mathrm{m}}=435 \mathrm{~nm}\right)$ incident on the surface of the leaf was determined in a way that the scattering of the incidental light was minimal.

Chloroplasts and PSII particles were obtained by the method in [13]. An aqueous solution of n-dodecyl$\beta$-D-maltoside (DM) (10\%) was added to isolated PSII particles (Chl concentration $=2 \mathrm{mg} / \mathrm{mL}$ in $50 \mathrm{mM}$ Mes buffer ( $\mathrm{pH}$ 6.0) with $10 \%$ (w/v) glycerol and $1 \mathrm{M}$ sucrose) at a DM/Chl ratio of $10: 1(\mathrm{w} / \mathrm{w})$ and incubation was performed at $4^{\circ} \mathrm{C}$ for $45 \mathrm{~min}$. Next, three volumes of $50 \mathrm{mM}$ Mes buffer ( $\mathrm{pH}$ 6.5) were added and centrifugation was performed at $28000 \mathrm{~g}$ for $20 \mathrm{~min}$ at $4^{\circ} \mathrm{C}$. The supernatant, with a concentration of Chl $=15 \mu \mathrm{g} / \mathrm{mL}$, was used for electrophoresis. Under these conditions, the supernatant contained predominantly PSII with a small amount of LHC II.

For nondenaturing polyacrylamide gel electrophoresis (PAGE), CPC were solubilized from thylakoid membranes. For the solubilization, membranes $(15 \mu \mathrm{g} / \mathrm{mL} \mathrm{Chl})$ were mixed with a solution of $0.45 \%$ DM, $0.1 \%$ lithium dodecyl sulfate (LDS), $10 \%$ glycerol in $25 \mathrm{mM}$ Mes buffer, $\mathrm{pH} 6.5$ at a detergent/chlorophyll ratio of $20: 1(\mathrm{w} / \mathrm{w})$. After incubation for $30 \mathrm{~min}$ on ice, the samples were centrifuged at $45000 \mathrm{~g}$ for $20 \mathrm{~min}$. The supernatant was used for analysis.

The content of PSII dimers, PSII monomers and LHC aggregates in thylakoid membranes was monitored using polyacrylamide gel electrophoresis according to [14] with Deriphat-160 ( $\beta$, a-laurel D-iminopropiodinate) in $12 \%$ PAGE in cylindrical tubes. Electrophoresis was performed at $85 \mathrm{~V}$ in the dark at $4^{\circ} \mathrm{C}$.

For the determination of fluorescent parameters $\left(F_{\mathrm{v}}, F_{\mathrm{m}}, F_{0}\right)$, as well as low-temperature spectroscopy and pigment content, at least ten leaves were used in each experiment. All analyzes were repeated from three to seven times. The reliability of the experimental data was assessed using Student's $t$-test.

\section{RESULTS \\ PSII Activity}

Short-term heating of seedlings at $42^{\circ} \mathrm{C}$ was accompanied by a noticeable decrease in the maximum fluorescence quantum yield $F_{\mathrm{v}} / F_{\mathrm{m}}$, which characterizes the photochemical activity of PSII, from $0.75-0.77$ (control) to $0.50-0.55$ (in the experiment immediately after treatment) (Fig. 1). However, in 
this case, the value of the constant fluorescence of Chl $a\left(F_{0}\right)$ hardly changed. When thermally inactivated seedlings were kept in the light, a further decrease in the $F_{\mathrm{v}} / F_{\mathrm{m}}$ ratio was observed. Moreover, if the seedlings were incubated in the dark, this decrease occurs for a longer time (Fig. 2). In white light, the decrease in activity continued for approximately $10-$ $24 \mathrm{~h}$, and then some stabilization and gradual recovery were observed. The incubation of seedlings in a thermostat at room temperature $(20 \mathrm{~min})$ hardly affected the value of the maximum quantum yield.

The recovery of PSII activity and CPC electrophoretic mobility depended on the intensity and spectral quality of light at which the seedlings were kept. At the same illumination intensity, blue light was the most effective for recovery compared to white and red light (Fig. 2). The advantage of blue light was probably related to the activation of the synthesis of proteins involved in PSII recovery. Under dark conditions, hardly any recovery was observed. The inhibitor of protein synthesis chloramphenicol $(0.001 \mathrm{M})$ inhibited PA recovery (Fig. 2).

It was shown that the preliminary heating of seedlings at $40^{\circ} \mathrm{C}$ for $20 \mathrm{~min}$ led to an increase in primary heat resistance as well as to a noticeable increase in the rate of OEC and PSII repair after secondary heat shock (Fig. 3).

Three bands with maxima at 685, 695, and $735 \mathrm{~nm}$ were observed in the low-temperature fluorescence spectra of control and experimental plants. It is known that the first two bands reflect the state of chlorophyll in CPC PSII [15]. The maximum at $735 \mathrm{~nm}$ corresponds to the CPC of PSI. The amplitudes of the peaks at 685 and $695 \mathrm{~nm}$ noticeably changed immediately after heating, which led to an increase in the F735/F695 and F735/F685 nm ratios (Table 1). After $6 \mathrm{~h}$, these ratios were restored to their initial level in low intensity light. Such changes could also affect the results of CPC separation under nondenaturing electrophoresis conditions.

\section{Analysis Based on Polyacrylamide Gel Electrophoresis}

The method of nondenaturing electrophoresis allows maintaining protein-chlorophyll bonds and, thereby, investigating PSII subcomplexes under heat stress and the subsequent recovery of PSII activity.

The results of electrophoretic separation of preparations of thylakoid membranes isolated from the leaves of control unheated seedlings (lane 1 ) heated to $42^{\circ} \mathrm{C}$ (lane 3 ) and then recovered after $6 \mathrm{~h}$ (lane 2) and $24 \mathrm{~h}$ (lane 4) seedlings are shown in Fig. 4.

Five main pigmented fractions (bands), as well as free chlorophyll, were revealed. These fractions were represented by a (1) monomer, (2) dimer, and (4) trimer LHC II, (3) PSI CPC as well as a (5) dimer of the core complex PSII. Immediately after heating, the intensity of bands 2, 4, and 5 decreased and decreased

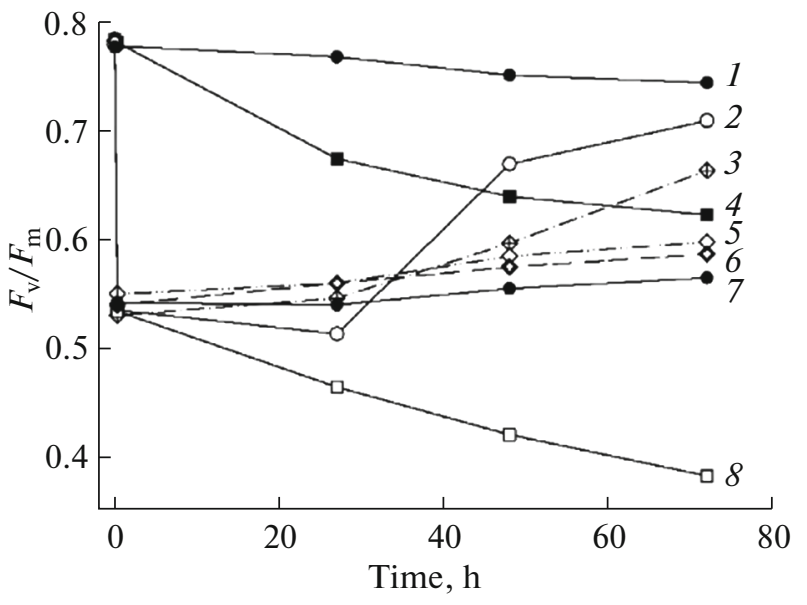

Fig. 2. Changes in the maximum quantum yield of PSII $\left(F_{\mathrm{v}} / F_{\mathrm{m}}\right)$ upon heating wheat seedlings at $42^{\circ} \mathrm{C}$ for $20 \mathrm{~min}$ in the dark and with subsequent poststress recovery under various light conditions: (1) seedlings not subjected to heating (control); (2) white LED light with an intensity of $100 \mu \mathrm{mol}$ quanta/( $\left.\mathrm{m}^{2} \mathrm{~s}\right)$; (5) white (3) blue, and (6) red LED light with an intensity of $8 \mu \mathrm{mol}$ quanta $/\left(\mathrm{m}^{2} \mathrm{~s}\right)$; (7 without light; (4) seedlings without heating + chloramphenicol (CA); (8) CA + heating and reduction at $100 \mu \mathrm{mol}$ quanta $/\left(\mathrm{m}^{2} \mathrm{~s}\right)$. Mean values of three independent experiments and their standard errors are shown.

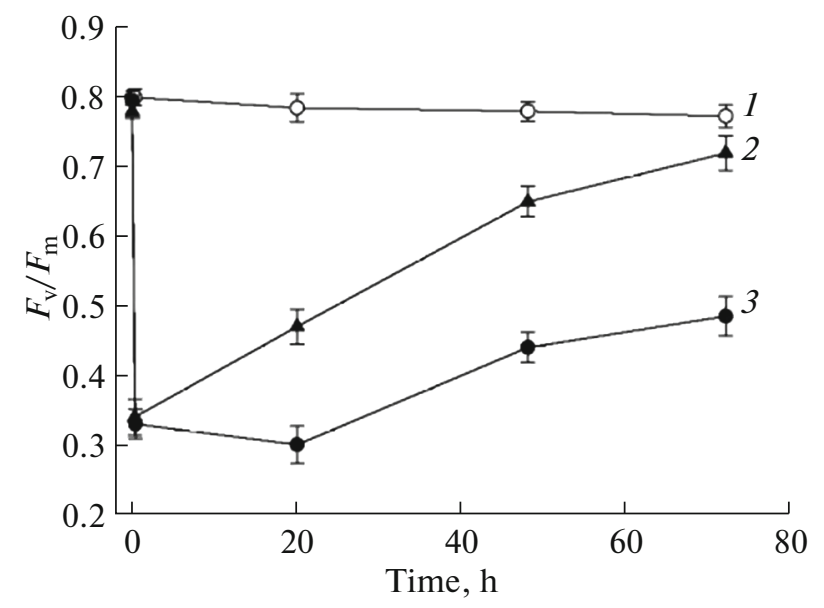

Fig. 3. Effect of pretreatment at $40^{\circ} \mathrm{C}$ on the recovery of PSII activity $\left(F_{\mathrm{v}} / F_{\mathrm{m}}\right)$ of wheat seedlings subjected to heat shock for $20 \mathrm{~min}$ at $43^{\circ} \mathrm{C}$ : (1) untreated plants (control); (2) after pretreatment at $40^{\circ} \mathrm{C}$, some plants were incubated for $24 \mathrm{~h}$ under white LED light $\left(I=40 \mu \mathrm{mol}\right.$ quanta $\left./\left(\mathrm{m}^{2} \mathrm{~s}\right)\right)$, then plants were subjected to heat shock $\left(20 \mathrm{~min}, 43^{\circ} \mathrm{C}\right)$ and incubated in the light $\left(20 \mu \mathrm{mol}\right.$ quanta/ $\left.\left(\mathrm{m}^{2} \mathrm{~s}\right)\right),(3)$ the other plants were not pretreated and were immediately subjected to heat shock at $43^{\circ} \mathrm{C}$. Mean values from five independent experiments and their standard errors are shown.

to a minimum after $6 \mathrm{~h}$ of exposure to relatively strong light $\left(1500 \mu \mathrm{M}\right.$ quanta $\left./\left(\mathrm{m}^{2} \mathrm{~s}\right)\right)$. At the same time, the appearance of the band at the start of lane 2 was observed, which, as we assumed, belongs to the CPC aggregates. This aggregate band disappeared $24 \mathrm{~h}$ after 


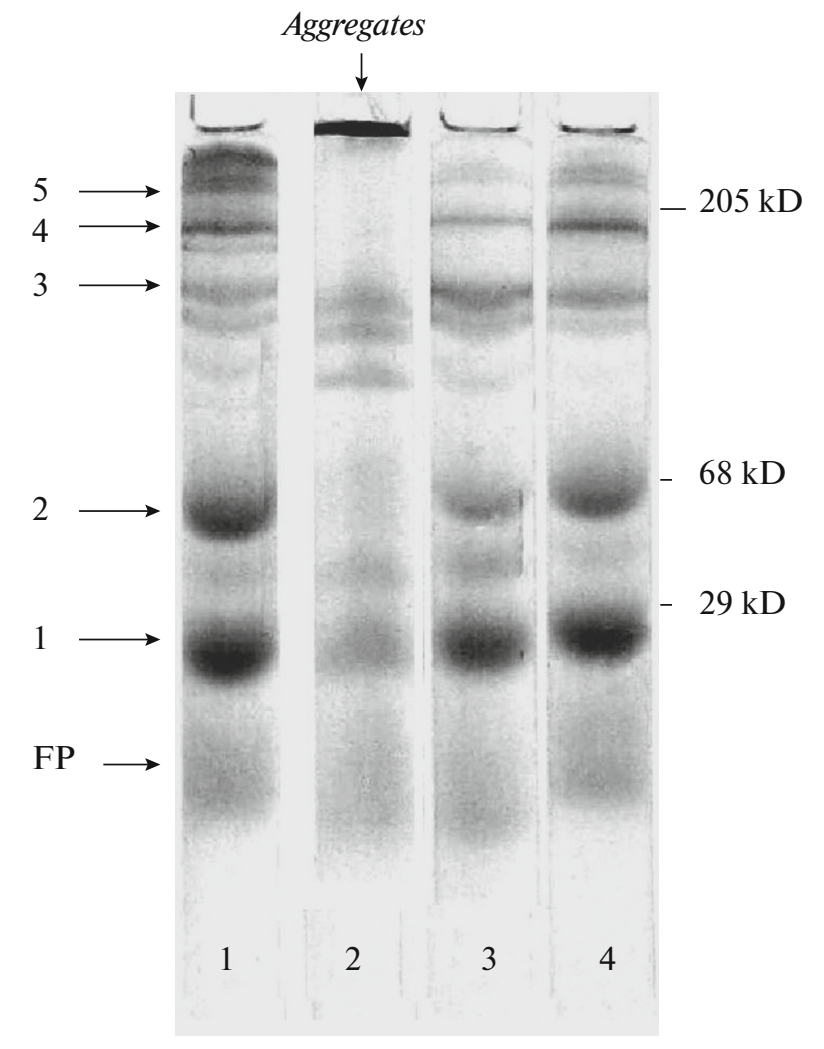

Fig. 4. Gel electrophoresis of CPC membranes isolated from the (1) leaves of unheated wheat seedlings and seedlings heated at $42^{\circ} \mathrm{C}(20 \mathrm{~min})$, then used for analysis after illumination $\left(I=300 \mu \mathrm{E} /\left(\mathrm{m}^{2} \mathrm{~s}\right)\right)$ for (3) 0 , (2) 6 , and (4) $24 \mathrm{~h}$. The suspension with a concentration of $\mathrm{Chl}=$ $25 \mathrm{mM} / \mathrm{mL}(25 \mu \mathrm{g} / \mathrm{gel})$ was loaded on electrophoresis tubes. Molecular weight markers were used: myosin, $25 \mathrm{kD}$; bovine serum albumin, $68 \mathrm{kD}$; carbonic anhydrase, $29 \mathrm{kD}$. Arrows show (1) monomer, (2) dimer, and (4) trimer of LHC II, (3) PSI complex, (5) core complex dimer of PSII, (FP) free pigments.

Table 1. Changes in the $F 735 / F 695$ and $F 735 / F 685$ ratios calculated based on the low-temperature fluorescence spectra at $77 \mathrm{~K}$ upon heating $\left(42^{\circ} \mathrm{C}, 20 \mathrm{~min}\right)$ and the subsequent recovery of wheat seedlings under light.

\begin{tabular}{c|l|l}
\hline Time, $\mathrm{h}$ & $F 735 / F 695$ & $F 735 / F 685$ \\
\hline 0 (control) & $4.0 \pm 0.15$ & $4.1 \pm 0.1$ \\
48 (control) & $4.1 \pm 0.3$ & $4.3 \pm 0.2$ \\
0 & $5.5 \pm 0.25$ & $4.8 \pm 0.15$ \\
6 & $3.6 \pm 0.15$ & $3.4 \pm 0.25$ \\
48 & $3.9 \pm 0.2$ & $3.9 \pm 0.2$ \\
\hline
\end{tabular}

Some seedlings were grown for $48 \mathrm{~h}$ at $20^{\circ} \mathrm{C}$ without any treatment (control), while others were thermally inactivated at $42^{\circ} \mathrm{C}$, then they recovered after heat treatment for 6 and $48 \mathrm{~h}$ under a white light $\left(I=60 \mu \mathrm{mol}\right.$ quanta/ $\left(\mathrm{m}^{2} \mathrm{~s}\right)$. The fluorescence spectra of leaf segments were recorded at wavelengths of 685,695 , and $735 \mathrm{~nm}$ at $\lambda_{\text {exc }}=435 \mathrm{~nm}(0)$ immediately after thermal inactivation and (6) $6 \mathrm{~h}$ and (48) $48 \mathrm{~h}$ after heat stress. Each value corresponds to an average of 5-7 measurements. The differences between the control and heat-stressed seedlings, except for line 0 , were insignificant $(P>0.01)$. heating and did not appear when heated seedlings were illuminated in low-intensity light $\left(40 \mu \mathrm{M}\right.$ quanta $\left./\left(\mathrm{m}^{2} \mathrm{~s}\right)\right)$ (data not shown).

\section{DISCUSSION}

PSII is one of the most sensitive PSA components under the influence of stress factors, in particular, high temperatures $[8,16]$. The oxygen evolution system is especially sensitive to heating, for example, thermal inactivation of the $\mathrm{O}_{2}$ evolution system occurs at rather low temperatures of $30-40^{\circ} \mathrm{C}$ according to Thompson et al. [17].

Most probably, heat stress acts on the donor side of PSII $[16,18]$, stimulating the release of the PsbO protein from the manganese-containing cluster, and then manganese ions, which leads to a decrease in Chl fluorescence [19]. These processes occur quickly and oxidative damage did not occur. The absence of changes in the basic fluorescence $F_{0}$ and $\mathrm{Chl}$ content in leaves, which we found at the studied temperatures, is consistent with the reversibility of inhibition of PSII activity. However, at a sufficiently high temperature, $F_{0}$ increased, which was interpreted as a result of the separation of LHC II from core complexes of PSII [20].

We revealed that the inhibition effect of PSII activity and photosynthesis increases with time when the seedlings are kept in a sufficiently strong light and the stronger the light intensity at which the seedlings are kept, the more pronounced the effect (Fig. 1). It can be suggested that after heat stress in the temperature range of $40-42^{\circ} \mathrm{C}$, photoinhibition occurs even at relatively low light intensities, and proteolysis of damaged proteins and synthesis of new proteins of photosystems are important for the recovery of the activity of OEC and PSII after inhibition.

CPC CP43 and CP47 play an important role in maintaining the structural integrity of PSII and its ability to evolve oxygen [21]. Isolated CP43 and CP47 complexes are usually characterized by low-temperature fluorescence emission bands at $77 \mathrm{~K}$ with maxima at 685 and $695 \mathrm{~nm}$ (F685 and F695), respectively [15]. Approximately the same maxima were also revealed when the fluorescence of native leaves was recorded [22]. Earlier, in our experiments on wheat leaves [4], three fluorescence bands were found: a long-wavelength band associated with PSI, and bands with maxima at approximately 695 and $685 \mathrm{~nm}$, which belong to PSII. A noticeable decrease in the intensity of bands with maxima at 685 and $695 \mathrm{~nm}$ was observed immediately after heating at $42^{\circ} \mathrm{C}$ (Table 1). Since the content of pigments after heating did not change significantly, we assumed that these decreases were associated with the redistribution of excitation energy from PSII to PSI due to the movement of LHC II into the stromal region. This is a reversible process and it can be assumed that the former energy distribution from the LHC to PSII is restored no later than $6 \mathrm{~h}$ after heat 
stress. The dynamics of changes in the electrophoretic mobility of green zones depended on the intensity of the light used for recovery. In strong light, after $6 \mathrm{~h}$, the content of CPC complexes decreased (Fig. 4), and the intense band found at the start of lane 2, associated with the aggregation of high molecular weight CPC, disappeared. These facts can be explained by the modification of proteins and CPC of PSII, primarily LHC II, under strong photoinhibition conditions. An increase in the F735/F695 and F735/F685 ratios may also indicate a redistribution of absorbed energy in favor of PSI. Such a protective effect against photoinhibition and heat stress has been described in the literature and may be associated with the aggregation of LHC II with part of the proteins of the PSII core complex [6, 22].

It was shown [23] that the loss of oxygen-releasing function precedes changes in the structure of the OEC and the dissociation of external Chl proteins of the core complex, for example, CP43 and CP47, as well as other complexes, followed by their proteolysis. This issue was studied in our experiments on the dynamics of changes in pigment-protein and submolecular PSII complexes. The poststress decrease in PSII photochemical activity with a lag period lasting several hours may support the assumption that endogenous mechanisms of PSII protein degradation are triggered. It is possible that heat stress led to the release of proteolytic enzymes from lysosomes or activation of peptidases localized in the thylakoid lumen. At the same time, the mechanisms restoring the biosynthesis of PSII proteins and their incorporation into damaged complexes are probably triggered. The fact that de novo synthesis of chloroplast proteins is, at least, partially necessary for the restoration of PSII activity follows from our data on the absence of a significant recovery of PSII activity in the presence of the inhibitor of protein synthesis chloramphenicol and the maximum recovery effect of blue light (Fig. 2).

We also studied the effect of thermal quenching, which is important for the recovery of the photochemical activity of PSII. It was shown that preliminary heating of seedlings at $40^{\circ} \mathrm{C}$ for $20 \mathrm{~min}$ led to a subsequent increase in primary thermal and photoresistance and to an increase in the rate of OEC and PSII repair after secondary heat shock (Fig. 3). These results suggest that heat-shock proteins may be involved in recovery, both after temperature shock and photoinhibition.

It is known that blue light induces protein biosynthesis and an increase in chlorophyll content in plants [24]. In addition, experiments with plant mutants with a phototropin deficiency and growing plants with different ratios of red and blue light have shown the positive effect of blue light, which is absorbed by cryptochromes and phototropins. It optimizes photosynthesis by stimulating the efficiency of light absorption, reducing photodamage, and regulating gas exchange between leaves and the atmosphere, in particular, increasing the photochemical activity of PSII $\left(F_{\mathrm{v}} / F_{\mathrm{m}}\right)$ $[25,26]$. It is assumed that these effects are a consequence of the optimal location of chloroplasts when the leaves are illuminated with blue light and the optimization of the functioning of stomata on the leaf surface, which is important for increasing the rate of $\mathrm{CO}_{2}$ absorption. This is consistent with the high efficiency of PSII recovery that is detected with a blue light. We also found that the recovery did not occur in the presence of the inhibitor of protein synthesis: chloramphenicol. Therefore, we assumed that the synthesis of proteins of photosystems, as well as efficient proteolysis of proteins damaged by stress, is important for the recovery of PSII during photoinhibition [4].

It was shown earlier [16] that high temperatures limit the ability of plants to use light energy and enhance the photoinhibition effect. This effect is probably also manifested during the poststress recovery of PSII since the recovery of PSII under a strong light was significantly slowed down compared to the recovery under low intensity light (Fig. 1).

Thus, heating of wheat seedlings for $20 \mathrm{~min}$ at $42^{\circ} \mathrm{C}$ and their subsequent exposure to high intensity light stimulated the aggregation of LHC II, as well as monomers and dimers of PSII. These changes correlated with a decrease in PSII activity, which, in a sufficiently strong light, was probably due to structural rearrangements and CPC modification. It can also be assumed that aggregation and structural and functional changes in the CPC of photosystems are defense mechanisms increasing the dissipation of excessive excitation energy.

\section{COMPLIANCE WITH ETHICAL STANDARDS}

Conflict of interests. The authors declare that they have no conflicts of interest.

Statement on the welfare of humans or animals. This article does not contain any studies involving humans or animals performed by any of the authors.

\section{OPEN ACCESS}

This article is licensed under a Creative Commons Attribution 4.0 International License, which permits use, sharing, adaptation, distribution and reproduction in any medium or format, as long as you give appropriate credit to the original author(s) and the source, provide a link to the Creative Commons license, and indicate if changes were made. The images or other third party material in this article are included in the article's Creative Commons license, unless indicated otherwise in a credit line to the material. If material is not included in the article's Creative Commons license and your intended use is not permitted by statutory regulation or exceeds the permitted use, you will need to obtain permission directly from the copyright holder. To view a copy of this license, visit http://creativecommons.org/licenses/by/4.0/. 


\section{REFERENCES}

1. Adir, N., Zer, H., Shochat, S., and Ohad, I., Photoinhibition-a historical perspective, Photosynth. Res., 2003, vol. 76, p. 343.

2. Demmig-Adams, B., Cohu, C.M., Muller, O., and Adams, W.W. III, Modulation of photosynthetic energy conversion efficiency in nature: from seconds to seasons, Photosynth. Res., 2012. V.113, p. 75.

3. Khristin, M.S., Kreslavskii, V.D., and Khorobrykh, A.A., Recovery of photosystem 2 after short-term heating of wheat leaves, Vestn. Bashkir. Gos. Univ., 2001, vol. 2, p. 84.

4. Kreslavski, V.D. and Khristin, M.S., Aftereffect of heat shock on fluorescence induction and low-temperature fluorescence spectra of wheat leaves, Biophysics (Moscow), 2003, vol. 48, p. 806.

5. Kadir, S. and von Weihe, M., Photochemical efficiency and recovery of photosystem II in grapes after exposure to sudden and gradual heat stress, J. Am. Soc. Hortic. Sci., 2007, vol. 132, p. 751.

6. Tang, Y., Wen, X., Lu, O., Yang, Z., Cheng, Z., and $\mathrm{Lu}, \mathrm{C}$., Heat stress induces an aggregation of the lightharvesting complex of photosystem II in spinach plants, Plant Physiol., 2007, vol. 143, p. 629.

7. Havaux, M., Short-term responses to photosystem I to heat stress, Photosynth. Res., 1996, vol. 47, p. 85.

8. Schrader, S.M., Wise, R.R., Wacholtz, W.F., Ort, D.R., and Sharkey, T.D., Thylakoid membrane responses to moderately high leaf temperature in Pima cotton, Plant Cell Environ., 2004, vol. 27, p. 725.

9. Allakhverdiev, S.I., Los, D.A., Mohanty, P., Nishiyama, Y., and Murata, N., Glycinebetaine alleviates the inhibitory effect of moderate heat stress on the repair of photosystem II during photoinhibition, Biochim. Biophys. Acta, Bioenerg., 2007, vol. 1767, p. 1363.

10. Kreslavski, V.D., Balakhnina, T.I., Khristin, M.S., and Bukhov, N.G., Pretreatment of bean seedlings by choline compounds increases the resistance of photosynthetic apparatus to UV radiation and elevated temperatures, Photosynthetica, 2001, vol. 39, p. 353.

11. Kreslavski, V., Tatarinzev, N., Shabnova, N., Semenova, G., and Kosobryukhov, A., Characterization of the nature of photosynthetic recovery of wheat seedlings from short-term dark heat exposures and analysis of the mode of acclimation to different light intensities, J. Plant Physiol., 2008, vol. 165, p. 1592.

12. Goltsev, V.N., Kalaji, H.M., Paunov, M., Bąba, W., Horaczek, T., Mojski, J., Kociel, H., and Allakhverdiev, S.I., Variable chlorophyll fluorescence and its use for assessing physiological condition of plant photosynthetic apparatus, Russ. J. Plant Physiol., 2016, vol. 63, p. 869 .

13. Kuwabara, T. and Murata, N., An improved purification method and a further characterization of the 33-kilodalton protein of spinach chloroplasts, Biochim. Biophys. Acta, Bioenerg., 1982, vol. 680, p. 210.

14. Peter, G.F. and Thornberg, J.P., Biochemical composition and organization of higher plants photosynthem 2 light-harvesting pigment-proteins, J. Biol. Chem., 1991, vol. 266, p. 16745 .
15. Dekker, J.P., Hassold, A., Petterson, A., van Roon, H., Groot, M.-L., and van Grondelle, R., On the nature of the F695 and F685 emission of photosystem II, in Photosynthesis: From Light to Biosphere, Mathis, P., Ed., Dordrecht: Kluwer, 1995, vol. 1, p. 53.

16. Allakhverdiev, S.I., Kreslavski, V.D., Klimov, V.V., Los, D.A., Carpentier, R., and Mohanty, P., Heat stress: an overview of molecular responses in photosynthesis, Photosynth. Res., 2008, vol. 98, p. 541.

17. Thompson, L.K., Blaylock, R., Sturtevant, J.M., and Brudvig, G.W., Molecular basis of the heat denaturation of photosystem II, Biochemistry, 1989, vol. 28, p. 6686.

18. Mohanty, P., Kreslavski, V.D., Klimov, V.V., Los, D.A., Mimuro, M., Carpentier, R., and Allakhverdiev, S.I., Heat stress: susceptibility, recovery and regulation, in Photosynthesis: Plastid Biology, Energy Conversion and Carbon Assimilation, Adv. Photosynth. Respir. Ser., vol. 34, Eaton-Rye, J., Tripathy, B., and Sharkey, T., Eds., Dordrecht: Springer-Verlag, 2012, vol. 34.

19. Yamane, Y., Kashino, Y., Koike, H., and Satoh, K., Effects of high temperatures on photosynthetic systems in spinach: Oxygen-evolving activities, fluorescence characteristics and the denaturation process, Photosynth. Res., 1998, vol. 57, p. 51.

20. Yamane, Y., Kashino, Y., Koike, H., and Satoh, K., Increases in the fluorescence F0 level and reversible inhibition of Photosystem II reaction center by high temperature treatments in high plants, Photosynth. Res., 1997, vol. 52, p. 57.

21. Bricker, T.M. and Ghanotakis, D.F., Introduction to oxygen evolution and the oxygen-evolving complex, in Oxygenic Photosynthesis: The Light Reactions, Ort, D.R. and Yocum, C.F., Eds., Dordrecht: Springer-Verlag, 1996, p. 113.

22. Cajanec, V., Stroch, M., Lachetova, I., Kalina, J., and Spunda, V., Characterization of the photosystem II inactivation of heat-stressed barley leaves as monitored by the various parameters of chlorophyll $a$ fluorescence and delayed fluorescence, J. Phochem. Photobiol., 1998, vol. 47, p. 39.

23. Nash, D., Miyao, M., and Murata, N., Heat inactivation of oxygen evolution in photosystem II particles and its acceleration by chloride depletion and exogenous manganese, Biochim. Biophys. Acta, Bioenerg., 1985, vol. 807, p. 127.

24. Voskresenskaya, N.P., Control of the activity of the photosynthetic apparatus in higher plants, in Blue Light Effects in Biological Systems, Senger, H., Ed., Berlin: Springer-Verlag, 1984, p. 407.

25. Takemiya, A., Inoue, S., and Doi, M., Phototropins promote plant growth in response to blue light in low light environments, Plant Cell, 2005, vol. 17, p. 1120.

26. Zheng, L. and van Labeke, M.-C., Long-term effects of red- and blue-light emitting diodes on leaf anatomy and photosynthetic efficiency of three ornamental pot plants, Front. Plant Sci., 2017, vol. 9, p. 917.

Translated by V. Mittova 